\title{
The Synthesis and Characterization of New Polymerizable Pyrimidines: Immobilization of the Monomers onto Hydrophilic Graft Copolymeric Supports Through Radiation-Induced Copolymerization-Grafting
}

\author{
S. PEGIADOU, ${ }^{1}$ J. T. GUTHRIE, ${ }^{2}$ M. H. GILL $^{3}$ \\ ${ }^{1}$ The Department of Chemistry, The University of Thessaloniki, 54006 Thessaloniki, Greece \\ ${ }^{2}$ The Department of Colour Chemistry, The University of Leads, Leads LS2 9JT, United Kingdom \\ ${ }^{3}$ The Department of Chemistry, The University of Coimbra, Coimbra 3049, Portugal
}

Received 9 July 1997; accepted 18 January 1998

\begin{abstract}
Polymerizable quaternary allyl-pyrimidinium salts, that is, 1-allyl-4amino-5-phenyl-pyrimidine (IV), 1-allyl-4-acetamido-5-phenyl-pyrimidine (V), 1-allyl5-hydroxymethylamino-5-phenyl-pyrimidine (VI), and 1-allyl-pyrimidine (VIII) bromides, as well as 4-acrylamido-5-phenyl-pyrimidines II' and IV', were synthesized and characterized. Three of the activated pyrimidine derivatives, the two acrylamido and one allyl pyrimidine, were immobilized onto (Agar-g-co-HEMA)-X-TMPTA via graft copolymerization. Each copolymer system, based on 2-hydroxyethyl methacrylate (HEMA) grafted onto Agar followed by crosslinking with trimethyllopropane triacrylate (TMPTA), was prepared by radiation-induced copolymerization carried out in the simultaneous mode. The release properties of the immobilized pyrimidines were assessed in various aqueous media over a period of approximately 22 days. () $1998 \mathrm{John}$ Wiley \& Sons, Inc. J Appl Polym Sci 70: 211-218, 1998
\end{abstract}

Key words: allyl pyrimidines; quaternary pyrimidinium salts; quaternary allyl pyrimidines; polymerizable allyl pyrimidines; acrylamido pyrimidines; immobilization of polymerizable pyrimidines; graft copolymerization

\section{INTRODUCTION}

Various functional pyrimidines have been reported. Pitha et al. ${ }^{1,2}$ and Ueda et al. ${ }^{3,4}$ have described the preparation and polymerization of various $N$-vinyl pyrimidines and purines. In their studies, the authors used these linear polymers together with the heterocyclic-base substituent as model systems for nucleic acids. 5-Vinyl uracil has been synthesized by Fyssekis et al. ${ }^{5}$ This

Correspondence to: S. Pegiadou.

Journal of Applied Polymer Science, Vol. 70, 211-218 (1998)

(C) 1998 John Wiley \& Sons, Inc. monomer was used in studies of the intermolecular forces, which originate in nucleic acids. It has also been used to assist in the chromatographic separation of nucleic acid components. Many articles in this field have been published. ${ }^{6-12}$

However, information concerning allyl polymers and copolymers based on the pyrimidine and on the purine series is very limited. Allyl polymers and copolymers generally have been proposed for use as plasticizers, adhesives, and also as crosslinking agents. Various patents have been granted in such areas of application. ${ }^{13}$

There are several difficulties and peculiarities that are inherent to the polymerization of allyl 
monomers. An example is given by the general achievement of low-molar-mass polymers, arising from free radical initiation routes because of the ability of the allyl radical to self-stabilize through resonance. ${ }^{13}$ There is also the possibility of cyclisation, leading to 5- or 6-membered ring structures, especially with diallyl amines during attempts at free radical addition polymerization. ${ }^{14}$

Matsumoto et al. ${ }^{15-17}$ have reported anomalous head-to-head addition sequences in the radical polymerization of allylic monomers. In their study, this group made comparisons with the corresponding vinyl monomers.

Paleos and coworkers ${ }^{18,19}$ have provided information concerning the polymerization of allyl and diallyl quaternary ammonium salts. This group used irradiation procedures to provide polymers whose mean molar mass values were approximately $11.000 \pm 1000$ Daltons. The polymers, obtained by polymerization of these surfactant monomers, under micellar conditions, are interesting because of their application as drug carriers and as biomimetic agents for reactivity control.

So the pyrimidine ring system, condensed or otherwise, is still very interesting, because it has been widely used in a variety of antibacterial applications and other applications, including drugs, antibiotics, analgesics, and antitumour agents. ${ }^{20-23}$ Selective functionalization of the pyrimidine ring provides the opportunity for its conversion to a polymerizable system suitable for use in an encapsulated or covalently attached form.

The subject of biocatalyst immobilization on graft copolymeric supports is now well established. ${ }^{24-28}$ Gel entrapment has also received a great deal of attention. ${ }^{29-32}$ Each of these approaches is characterized by the development of a suitable polymer matrix, consideration of immobilization coupling procedures, assessment of coupling effectiveness, features relevant to stability and suitability for recycling, release mechanisms, and the significance of microenvironmental factors. ${ }^{33,34}$

Our interests lie in immobilization biotechnology, particularly with respect to cells and antibodies $^{35}$ and to enzymes. ${ }^{36-38}$

More recently, we have interested in the use of covalent linkage, coupled with crosslinking, to provide a means of effective immobilization of selected drugs. ${ }^{39,40}$ When the support system is highly hydrophilic, though still crosslinked, very effective supports have been generated. In this report, we describe our studies involving the synthesis of selected allyl and acrylamido pyrimi- dines containing reactive functional groups. Characterization of the monomers has been undertaken using spectroscopic and analytical techniques. Three differently functionalized pyrimidines have been immobilized, by entrapment-covalent linkage, onto a graft copolymer based on 2-hydroxyethylmethacrylate (HEMA), simultaneously grafted onto agar while the entire system is subjected to controlled crosslinking using trimethylopropane triacrylate (TMPTA) ${ }^{41}$ The product is symbolized as (Agar-g-co-HEMA)-XTMPTA.

\section{EXPERIMENTAL}

\section{Reagents}

Pyrimidine (Aldrich Chem. Co) was used as supplied. Allyl bromide (Fluka Chem. purum) was used as supplied. Formaldehyde solution was supplied by BDH Chem. Ltd., Poole, UK. Acryloyl chloride, formalin, and hydroxyethyl methacrylate were supplied by Aldrich Chemical Co. Ltd., Gillingham, UK. Trimethylopropane triacrylate was supplied by U.C.B. (Belgium). The agar was obtained from Sicomol Ltd., Figueira da Foz, Portugal.

\section{Preparation of Starting Materials}

The 4-amino-5-phenyl-pyrimidine (I) and 4-acetamido-5-phenyl-pyrimidine (II) were prepared according to the procedures described in the literature. $^{42-44}$ For the 4-hydroxymethylamino-5phenyl-pyrimidine (III) $1.71 \mathrm{~g}$ (0.01 mol) of (I) was added to $15 \mathrm{~cm}^{3}$ of formaldehyde solution (30\%), heated gently for $10 \mathrm{~min}$ until the sample was completely dissolved and then cooled with stirring over $30 \mathrm{~min}$. The solution was poured into cooled water and chilled to $5^{\circ} \mathrm{C}$ overnight. The resulting precipitate was filtered, washed with cold water, and then dried at $60^{\circ} \mathrm{C} .{ }^{45}$ The resulting white crystals (yield 77\%) gave the following information.

Melting point (mp): $135-136^{\circ} \mathrm{C}$; Infrared (IR) analysis $(\mathrm{KBr}) \mathrm{cm}^{-1}, 3300(\mathrm{NH}) ; 3100(\mathrm{OH}) ; 1580(\mathrm{C}=\mathrm{N})$. Nuclear magnetic resonance (NMR): $\left(\mathrm{CDCl}_{3}, \delta\right) 8.58 \mathrm{~S}$ (1H); $8.11 \mathrm{~S}(1 \mathrm{H}) ; 7.50-7.58 \mathrm{~m}(5 \mathrm{H}) ; 6.07 \mathrm{Sbr}(1 \mathrm{H})$; $4.93 \mathrm{~d}(2 \mathrm{H})$. Mass spectroscopy (MS): $\mathrm{m} / z, 201(14) \mathrm{M}^{+}$; 183 (20); 170 (100); 156 (19); 143 (17); 128 (15); 117 (10); $102(45)$.

ANAL. Calcd for $\mathrm{C}_{11} \mathrm{H}_{11} \mathrm{ON}_{3}: \mathrm{C}, 65.67 \% ; \mathrm{H}, 5.4 \%$; $20.89 \%$ Found: C, $65.65 \%$; H, 5.5\%; N, $20.85 \%$.

The monomers' syntheses are summarized in Scheme 1 


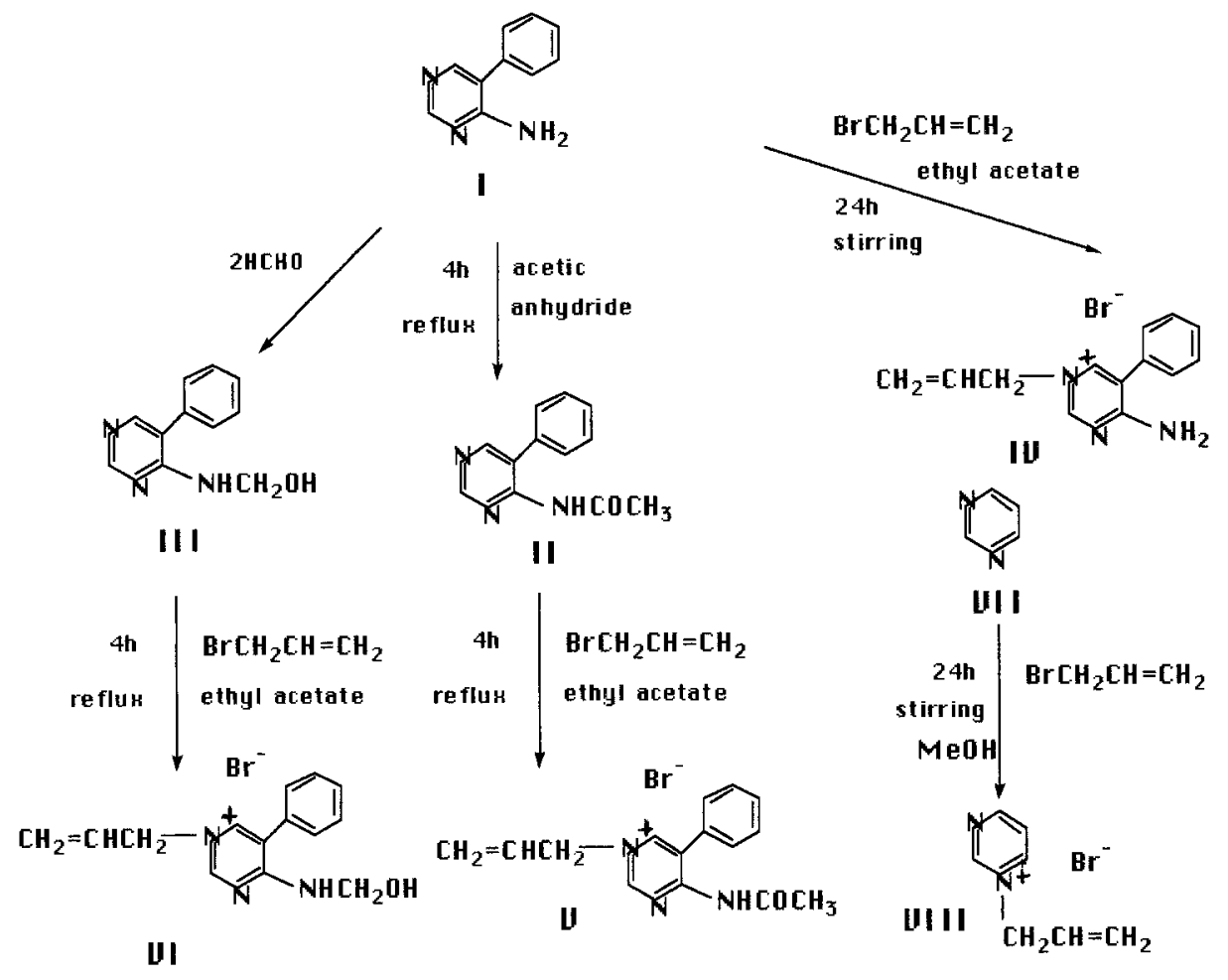

Scheme 1

The structural assignments of the monomers (IV), (V), (VI), and (VIII) were made on the basis of elemental and spectroscopic analysis (IR, NMR, MS) of the purified products, and the results are summarized in Table I.

The IR spectra were obtained using a UNICAM SP 1100 spectrophotometer. NMR spectra reported in $\delta$ units, were recorded on a JEOL FX 90 $\mathrm{Q}$, and the mass spectra were measured using a KRATOS MS-25 mass spectrometer at an ionization energy of $50 \mathrm{eV}$.

Elemental analysis were performed with a Carlo Erba analyzer, Model 1106. The specific synthesis procedures of the monomers are as follows. For 1-Allyl-4-amino-5-phenyl pyrimidine bromide (IV), 1-Allyl-4-acetamido-5-phenyl pyrimidine bromide (V), 1-Allyl-4-hydroxymethylamino-5-phenyl pyrimidine bromide (VI), and 1-Allyl-pyrimidine bromide (VIII), $0.01 \mathrm{~mol}$ of parent compounds (I), (II), (III), and (VII), respectively, and $0.015 \mathrm{~mol}$ of allyl bromide were added to $20 \mathrm{~cm}^{3}$ of ethyl acetate for the synthesis of compounds (IV), (V), and (VI). $\mathrm{MeOH}$ was used in the synthesis of compound (VIII). The quaternization were carried out with stirring over $24 \mathrm{~h}$ for compound VIII and under reflux $4 \mathrm{~h}$ for $(\mathrm{V})$ and $(\mathrm{VI})$. The quaternary salts were precipitated after cooling the residue. ${ }^{19}$ Recrystallization occurred using water. White crystals were obtained. The progress of the reactions was checked using thin layer chromatography (silica gel; methanol : chloroform $1: 1$ ).

Synthesis of 4-N-(Bis)Acrylamido-5-phenylpyrimidine [Compound (II')] and 4-N-(Acrylamido) aminomethyl-acrylyl 5-phenyl-pyrimidine [Compound (IV')]

$0.01 \mathrm{Mol}$ of the compounds I or III (see Scheme 2) respectively were added to $20 \mathrm{~cm}^{3}$ of a $20 \% \mathrm{KOH}$ solution in $7 \mathrm{~cm}^{3}$ of dioxan. Acryloyl chloride $\left(2 \mathrm{~cm}^{3}\right)$ was poured into this suspension with stirring. The mixture was cooled with occasional shaking for about 10 minutes.

A further $2 \mathrm{~cm}^{3}$ of acryloyl chloride were then added to the mixture. The reaction was cooled with occasional shaking. The products were poured into $20 \mathrm{~cm}^{3}$ of chilled water. The resulting precipitate was filtered, washed with cold water and dried under vacuum at $40^{\circ} \mathrm{C}$.

Compound (II') A yellow powder was obtained with a yield of $45 \%$. The melting range was $156-158^{\circ}$ C. The I.R. analysis in $\mathrm{KBr}$ show peaks at $3300 \mathrm{~cm}^{-1}$ for the $\mathrm{NH}$ group, 1650 $\mathrm{cm}^{-1}$ for the $\mathrm{C}=\mathrm{O}$ group and $1850 \mathrm{~cm}^{-1}$ for the $-\mathrm{C}=\mathrm{N}$-group. 
Table I Elemental Analysis, Spectral Data, Yields, and Melting Points (mp) of Monomers IV, V, VI, and VIII

\begin{tabular}{|c|c|c|c|c|c|}
\hline Compound & Formula & Yield & $\mathrm{mp}$ & Spectral Data & Elemental Analysis \\
\hline IV & $\mathrm{C}_{13} \mathrm{H}_{14} \mathrm{~N}_{3} \mathrm{Br}$ & $90 \%$ & $233-234^{\circ} \mathrm{C}$ & $\begin{array}{l}\text { IR }(\mathrm{KBr}) \mathrm{cm}^{-1}: 3300\left(\mathrm{NH}_{2}\right) \\
3120(\mathrm{C}=\mathrm{C}) ; 1650(\mathrm{C}=\mathrm{N}) \\
\mathrm{NMR}\left(\mathrm{D}_{2} \mathrm{O}, \delta\right): 8.69 \mathrm{~S} \\
(1 \mathrm{H}) ; 8.66 \mathrm{~S}(1 \mathrm{H}) ; 7.50- \\
8.10 \mathrm{~m}(5 \mathrm{H}) ; 5.10-6.30 \\
\text { m }(1 \mathrm{H}) ; 4.80 \mathrm{tr} .(2 \mathrm{H}) ; \\
4.60 \mathrm{~d}(2 \mathrm{H}) . \mathrm{MS}: \mathrm{m} / z \\
250(40) ; 210(100) ; 170 \\
(63) ; 143(15) ; 143(15) ; \\
102(17) ; 80(18) .\end{array}$ & $\begin{array}{l}\text { Calc:C, 53.42\%; H, 4.79\%; } \\
\text { N, } 14.38 \% ; \mathrm{Br}, 27.39 \% \text {. } \\
\text { Found: C, 53.75\%; H, } \\
\text { 4.85\%; N, } 14.85 \% ; \mathrm{Br}, \\
27.40 \% \text {. }\end{array}$ \\
\hline $\mathrm{V}$ & $\mathrm{C}_{15} \mathrm{H}_{16} \mathrm{ON}_{3} \mathrm{Br}$ & $65 \%$ & $157-158^{\circ} \mathrm{C}$ & $\begin{array}{l}\text { IR }(\mathrm{KBr}) \mathrm{cm}^{-1}: 3450(\mathrm{NH}) ; \\
3000(\mathrm{C}=\mathrm{C}) ; 1730(\mathrm{C}=\mathrm{O}) ; \\
1650(\mathrm{C}=\mathrm{N}) . \mathrm{NMR} \\
\left(\mathrm{CDCl}_{3}, \delta\right): 9.25 \mathrm{~S}(1 \mathrm{H}) ; \\
9.01 \mathrm{~S}(1 \mathrm{H}) ; 7.71-7.53 \mathrm{~m} \\
\text { (5H); 6.39-6.22 m (1H); } \\
\text { 6.12 tr. }(2 \mathrm{H}) ; 5.11 \mathrm{~d} \\
\quad(2 \mathrm{H}) ; 2.32 \mathrm{~S}(3 \mathrm{H}) . \mathrm{MS}: \\
\quad m / z 213(30) ; 201(20) ; \\
170(100) ; 156(30) ; 128 \\
(30) ; 102(38) ; 80(13)\end{array}$ & $\begin{array}{l}\text { Calc:C, 53.89\%; H, 4.79\%; } \\
\text { N, } 12.57 \% \text {; Br, } 23.95 \% \text {. } \\
\text { Found: C, 53.75\%; H, } \\
\text { 4.75\%; N, } 12.40 \% ; \mathrm{Br}, \\
24.05 \% \text {. }\end{array}$ \\
\hline VI & $\mathrm{C}_{14} \mathrm{H}_{16} \mathrm{ON}_{3} \mathrm{Br}$ & $70 \%$ & $162-163^{\circ} \mathrm{C}$ & 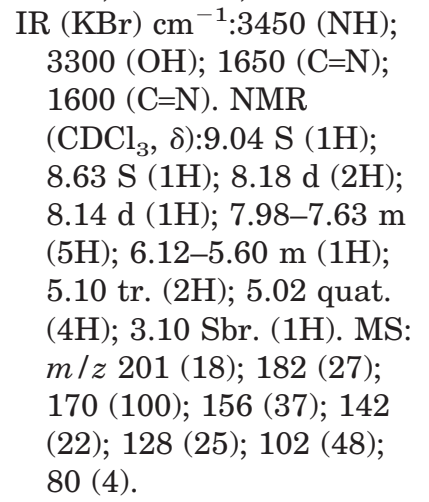 & $\begin{array}{l}\text { Calc:C, 52.17\%; H, 4.96\%; } \\
\text { N, 13.04\%; Br, 24.84\%. } \\
\text { Found: C, 52.0\%; H, } \\
5.05 \% ; \mathrm{N}, 13.3 \% ; \mathrm{Br}, \\
25.05 \% \text {. }\end{array}$ \\
\hline VIII & $\mathrm{C}_{7} \mathrm{H}_{9} \mathrm{~N}_{2} \mathrm{Br}$ & $20 \%$ & $139-140^{\circ} \mathrm{C}$ & $\begin{array}{l}\mathrm{IR}(\mathrm{KBr}) \mathrm{cm}^{-1}: 3000(\mathrm{C}=\mathrm{C}) \\
1640(\mathrm{C}=\mathrm{N}) . \mathrm{NMR}\left(\mathrm{D}_{2} \mathrm{O}\right. \\
\delta): 9.72 \mathrm{~S}(1 \mathrm{H}) ; 9.47 \mathrm{~d} \\
(1 \mathrm{H}) ; 9.31 \mathrm{~d}(1 \mathrm{H}) ; 8.28 \\
\text { tr. }(1 \mathrm{H}) ; 6.78-6.25 \mathrm{~m} \\
\quad(1 \mathrm{H}) ; 5.61 \mathrm{tr} .(2 \mathrm{H}) ; \\
5.40 \mathrm{~d}(2 \mathrm{H}) .\end{array}$ & $\begin{array}{l}\text { Calc:C, } 41.79 \% ; \mathrm{H}, 4.47 \% \text {; } \\
\text { N, } 13.93 \% ; \mathrm{Br}, 39.80 \% \text {. } \\
\text { Found: C, 41.35\%; H, } \\
\text { 4.55\%; N, } 14.10 \% ; \mathrm{Br}, \\
39.70 \% \text {. }\end{array}$ \\
\hline
\end{tabular}

M.S.: $\mathrm{m} / \mathrm{z} 279$ (1) $\mathrm{M}^{+} ; 225$ (5), 196 (12), 170 (100), 155 (4), 143 (21), 128 (4), 117 (13), 102 (15). Analysis: (\%) for $\mathrm{C}_{16} \mathrm{H}_{13} \mathrm{O}_{2} \mathrm{~N}_{3}$ : Calculated: $\mathrm{C}$, 68.88; H, 4.6; N, 15.05 Found: C, 68.35; H, 4.8; N, 15.25

Compound $\left(I V^{\prime}\right)$ Yellow powder (yield 40\%) with m.p. $=155-157^{\circ} \mathrm{C}$. I.R. (KBr) $\mathrm{cm}^{1} 3400(\mathrm{NH})$, $1650(\mathrm{C}=\mathrm{O}), 1580(\mathrm{C}=\mathrm{N})$ M.S.: $\mathrm{m} / \mathrm{z} 279(1.5)$ ( $\mathrm{M}^{=}$-HCHO), 225 (6), 197 (11), 170 (100), 155 (5),
143 (24), 128 (5), 117 (19), 102 (24). 128 (5), 117 (19), 102 (24). Analysis (\%) for $\mathrm{C}_{17} \mathrm{H}_{15} \mathrm{O}_{3} \mathrm{~N}_{3}$ : Calculated: C 66.01, H 4.85, N 13.59 Found: C 65.80, H 4.50, N, 13.2

Problems in solubility meant that it was not possible to acquire NMR spectra for monomeric products II' and IV'. However, characteristic mass spectra were obtained for these 2 monomers. Those monomers syntheses are summarized in Scheme 2. 

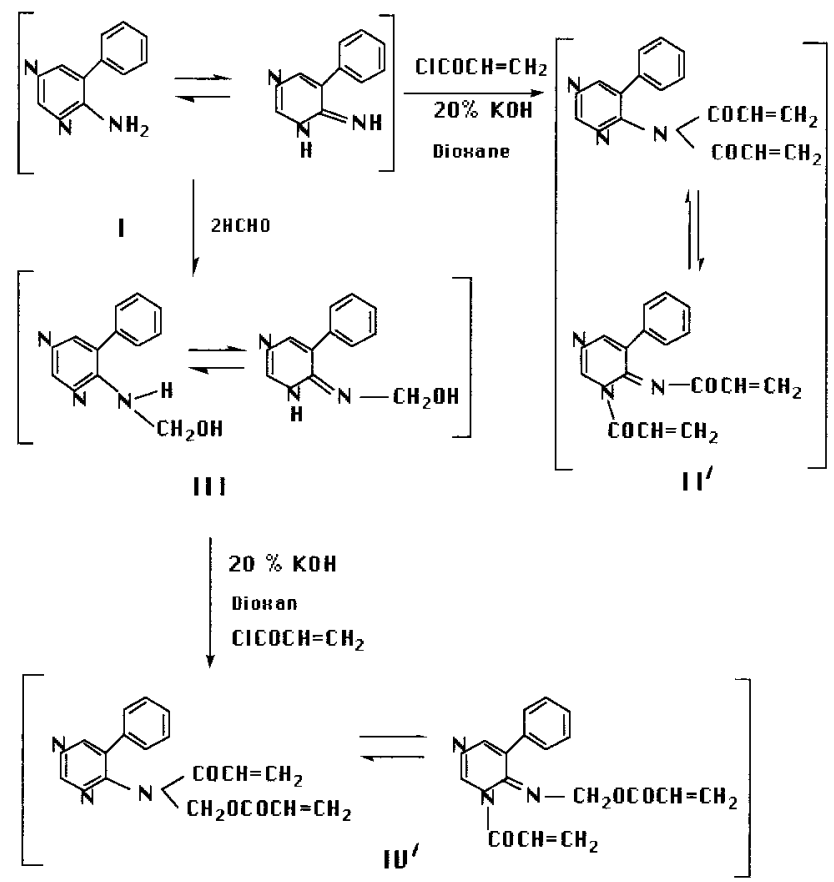

Scheme 2

The compounds $\mathrm{II}^{\prime}, \mathrm{IV}^{\prime}$, and V (100 mg) were immobilized by radiation-included copolymerization onto (Agar-g-co-HEMA)-x-TMPTA, as indicated above.

\section{Polymerization Procedures}

The pyrimidine derivatives (II', IV', or V) (100 $\mathrm{mg}$ ) were dissolved in a dimethyl-formamide

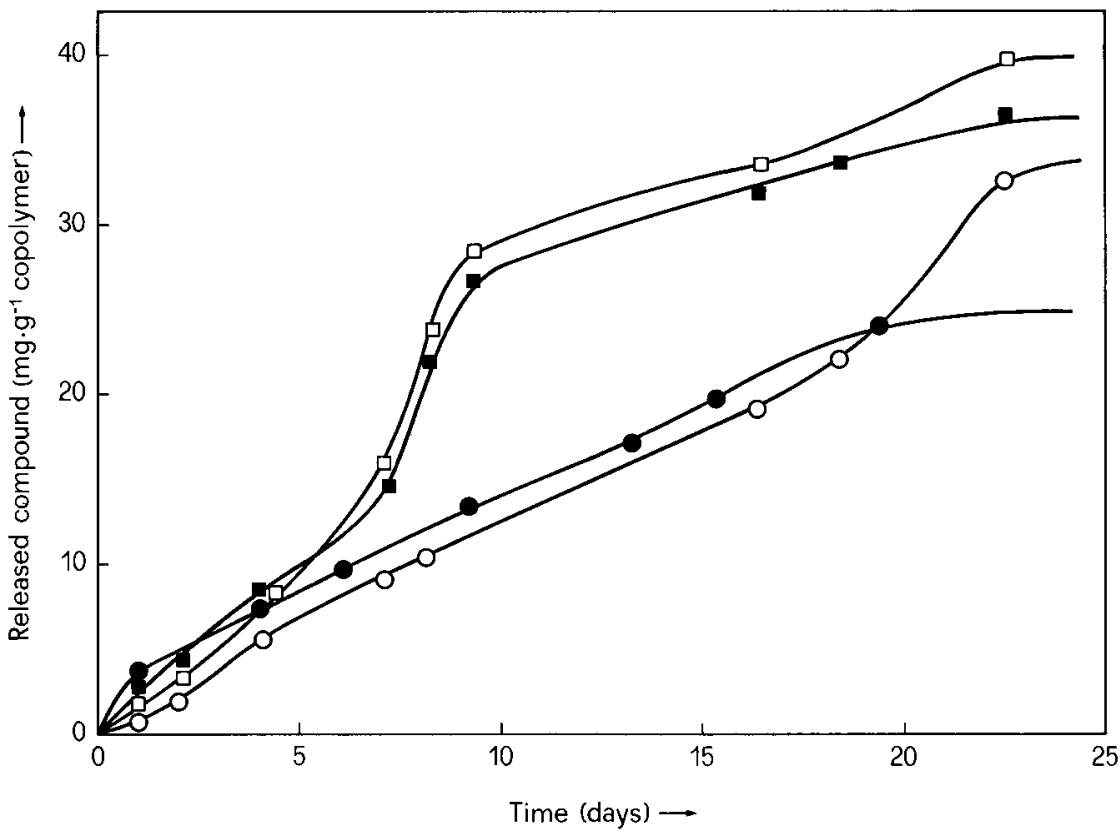

Figure 1 Variation in the release of compound $\mathrm{II}^{\prime}$ with time in various aqueous solutions: (@) physiological serum; (O) distilled water; $(\square) 0.1 M$ phosphate buffer, $\mathrm{pH}$ $7.3 ;(\mathbf{\square}) 0.01 M \mathrm{HCl}$ 


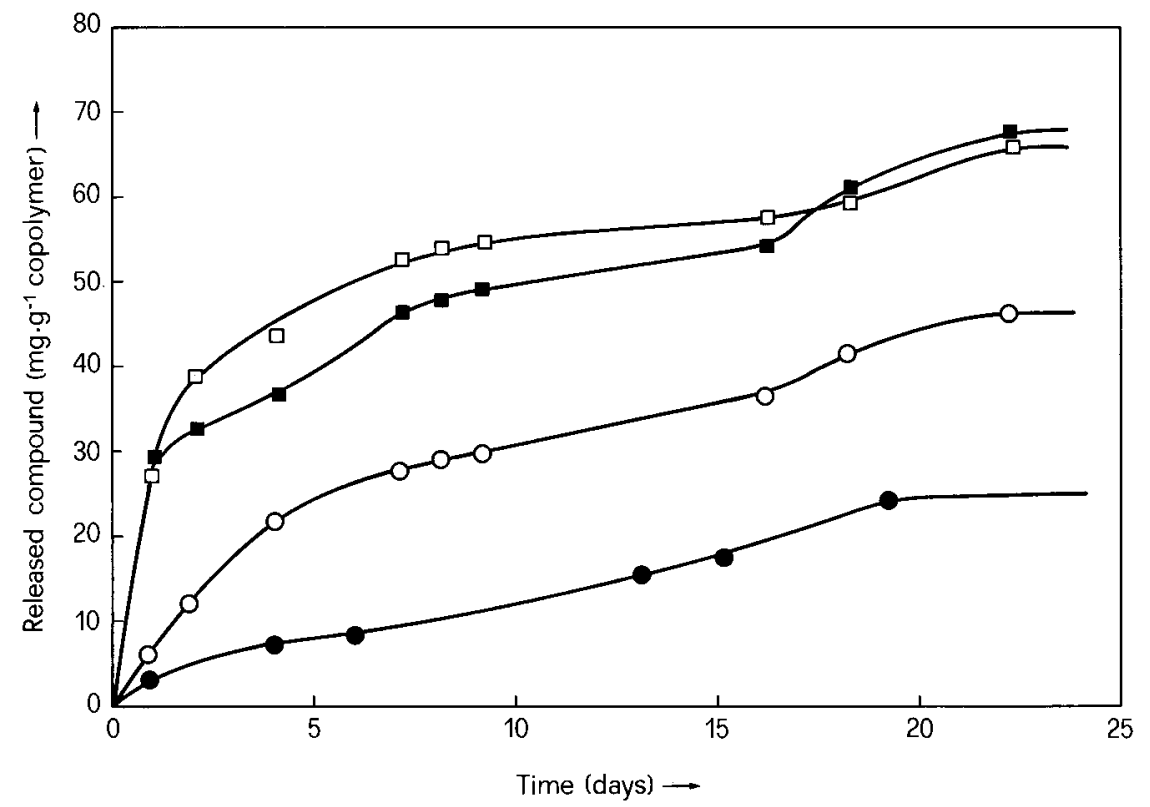

Figure 2 Variation in the release of compound IV' with time in various aqueous solutions: $(\bigcirc)$ physiological serum; $(\bigcirc)$ distilled water; $(\square) 0.1 M$ phosphate buffer, pH $7.3 ;(\square) 0.01 M \mathrm{HCl}$.

solution $\left(30 \mathrm{~cm}^{3}\right)$ containing $1.0 \mathrm{~g}$ of HEMA and $0.2 \mathrm{~g}$ of TMPTA. Then, $1.0 \mathrm{~g}$ of agar was introduced in this solution. The suspension was irradiated at $18.3 \mathrm{rad} \mathrm{s}^{-1}$ for $24 \mathrm{~h}$ at $25^{\circ} \mathrm{C}$, in the presence of air, on a ${ }^{60} \mathrm{Co}$ isotope source. The suspension was filtered and thoroughly washed with dimethylformamide and with water. The powder was then dried at constant weight, under vacuum at $40^{\circ} \mathrm{C}$. These procedures were repeated.

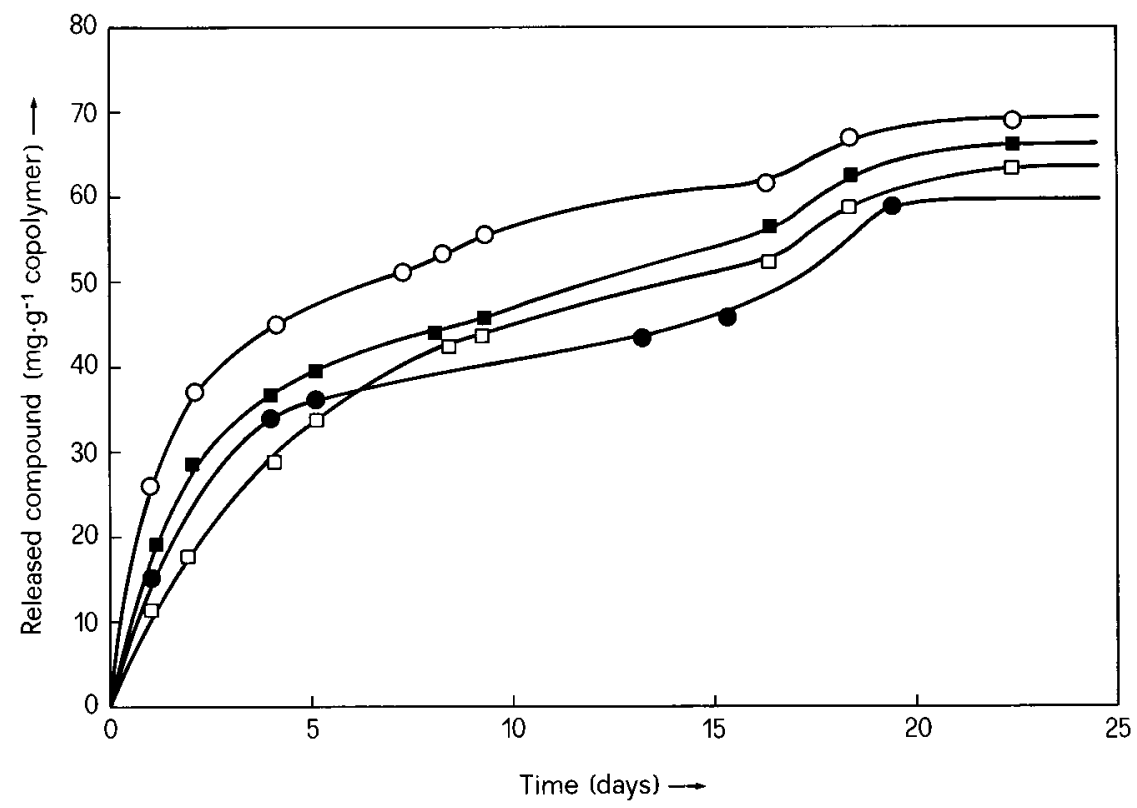

Figure 3 Variation in the release of compound $\mathrm{V}$ with time in various aqueous solutions: (@) physiological serum; $(\bigcirc)$ distilled water; $(\square) 0.1 M$ phosphate buffer, pH 7.3 ; $\mathbf{\square}) 0.01 M \mathrm{HCl}$. 
Table II Release of Pyrimidine Derivative (\% of Original Bound) After 22 Days, in Various Aqueous Media

\begin{tabular}{cccc}
\hline $\begin{array}{c}\text { Pyrimidine } \\
\text { Compound }\end{array}$ & Medium & $\begin{array}{c}\text { Released } \\
\text { Compound }\left(\mathrm{g}^{-1}\right) \\
\text { Copolymer }(\mathrm{mg})\end{array}$ & $\begin{array}{c}\text { Percentage Released } \\
\text { Relative to Initial Mass } \\
\text { of Compound Immobilized }\end{array}$ \\
\hline \multirow{2}{*}{$\mathrm{II}^{\prime}$} & $\mathrm{H}_{2} \mathrm{O} ; 0.1 M$ phosphate; & 33.7 & 56.6 \\
& buffer $\mathrm{pH}=7.3 ;$ & 37.5 & 63.0 \\
& $0.01 M \mathrm{HCl} ;$ & 41.2 & 69.2 \\
physiological serum & 24.7 & 41.5 \\
$\mathrm{IV}^{\prime}$ & $\mathrm{H}_{2} \mathrm{O} ; 0.1 M$ phosphate; & 47.3 & 64.4 \\
& buffer $\mathrm{pH}=7.3 ;$ & 68.7 & 94.1 \\
& $0.01 M$ HCl & 68.0 & 93.2 \\
$\mathrm{~V}$ & physiological serum & 24.8 & 34.2 \\
& $\mathrm{H}_{2} \mathrm{O} ; 0.1 M$ phosphate; & 70 & 95.9 \\
& buffer $\mathrm{pH}=7.3 ;$ & 67.3 & 82.8 \\
& $0.01 M$ HCl & 64.8 & 81.8 \\
\hline
\end{tabular}

\section{Release Determination of the Immobilized Pyrimidine Derivatives}

The samples containing the pyrimidine derivatives (prepared by irradiation, as indicated above) $(50 \mathrm{mg}$ ) were separately introduced in $5 \mathrm{~cm}$ of various aqueous media [distilled water, physiological serum, $0.1 M$ phosphate buffer $(\mathrm{pH}=7.0)$, and $10^{-2} M \mathrm{HCl}$. After known intervals of time, the samples were filtered and subsequently analyzed spectrophotometrically at $\lambda=400$ (for samples II' $^{\prime}$ and IV'$^{\prime}$ ) and at $\lambda=345$ for the sample V.

\section{RESULTS AND DISCUSSION}

The 3 monomers (IV), (V), and (VI) showed, in IR, peaks at $3400-3300 \mathrm{~cm}^{-1}$ for the NH group and all 4 allyl monomers peaks at $3100-3000 \mathrm{~cm}^{-1}$ for allylic $\mathrm{C}=\mathrm{C}$ group and peaks for $\mathrm{C}=\mathrm{N}$ (arom) at $1650-1600 \mathrm{~cm}^{-1}$.

The ${ }^{1} \mathrm{H}-\mathrm{NMR}$ spectra of all quaternary salts (IV, V, VI, and VIII) gave pyrimido protons peaks at $\delta 8.28-9.10 \mathrm{~S}$ and $\delta 9.04-9.72 \mathrm{~S}$ and multiple peaks for aromatic protons of the phenyl group at $\delta 8.10-7.50$. The allylic protons gave almost the same pattern, that is, peaks at $\delta 4.60-5.40$ (doublet) corresponding to $\mathrm{N}^{+}-\mathrm{CH}_{2}$ protons, peaks at $\delta$ 5.10-6.12 (triplet) corresponding to $\mathrm{C}=\mathrm{CH}_{2}$ protons and peaks at $\delta 5.10-6.78$ (multiplet) for the $\mathrm{CH}=\mathrm{CH}_{2}$ proton.

The mass spectra of compounds (IV), (V), and (VI) showed the same fragmentation pattern, although as it is well known for the quaternary salts, generally, there is not a molecular ion peak.
For $1 \mathrm{~g}$ aliquots of agar and $1 \mathrm{~g}$ aliquots of HEMA, together with $0.2 \mathrm{~g}$ of TMPTA, the (\%) grafting yields were 73.0, 59.6, and 59.6 for the pyrimidine compounds $\mathrm{II}^{\prime}, \mathrm{IV}^{\prime}$, and $\mathrm{V}$, respectively. This confirms that highly satisfactory yields were obtained in the copolymerization reactions.

The release characteristics of the pyrimidine compounds, after being immobilized, were assessed in various aqueous solutions for 22 days.

From the analysis of the results indicated in Figures 1-3 and Table II, we suggest that good yields of immobilization of the activated pyrimidines were obtained. It is clear that the watersoluble pyrimidine (V) is released more easily than is the less water-soluble compound (IV').

It is also clear that compound $\mathrm{V}$ gives similar levels of release in each of the continuous, storage media over the 22-day period (Fig. 3). Compounds II' and IV' show similar release behaviors in both neutral and acidic media $(0.1 M$ phosphate buffer and $0.01 \mathrm{M} \mathrm{HCl}$, respectively). However, the rate of release is more pronounced for compound IV' than it is for compound II' at equivalent periods of time. Compound IV' shows a rapid release profile from day 1 in $0.01 M$ phosphate buffer and $0.01 M \mathrm{HCl}$. This level of initial release is greater than that obtained, even with the water-soluble pyrimidine compound V.

Compounds $\mathrm{II}^{\prime}$ and $\mathrm{IV}^{\prime}$ show a slower, more continuous release behavior in physiological serum and in distilled water. Here, the behavior of compound IV' in physiological serum can be singled out for its very slow release characteristics. 
We should recall that while the experimental stages are duplicated, one cannot regulate the specific nature of the crosslinked, copolymeric assembly. Though the average extent of graftingcrosslinking may be identical on repetition, the location of such grafts and crosslinks could differ. This difference could influence the morphological nature of the drug-support composite.

The graft copolymers show promise with respect to their use in the immobilization of drugs. However, further parameters need to be considered. These include the influence of the monomer feed ratios, the temperature of reaction, and the dose rate on the composition of the copolymers. Such compositional variations will, in turn, influence the resulting immobilization capability and also the release characteristics of the immobilized drug composite.

\section{REFERENCES}

1. J. Pitha and POPTs O, J. Org. Chem., 33, 1341 (1968).

2. J. Pitha, P. M. Pitha, and POPTs O, Biochim. Biophys. Acta, 204, 39 (1970).

3. K. Kondo, H. Iwasaki, N. Ueda, K. Takemodo and M. Imoto, Makromol. Chem., 120, 21 (1968).

4. N. Ueda, K. Kondo, M. Kono, K. Takemodo, and M. Imoto, Makromol. Chem., 120, 13 (1968).

5. J. D. Fyssekis and F. Sweet, J. Org. Chem., 38, 264 (1973).

6. J. P. Jonak, S. F. Zakrzewski, and L. H. Mead, J. Med. Chem., 14, 408 (1971).

7. M. Muraoka, A. Takada, and T. Ueda, Chem. Pharm. Bull., 18, 261 (1970).

8. M. Muraoka, Y. Sedo, and T. Ueda, Chem. Pharm. Bull., 18, 269 (1970).

9. H. Schott, G. Greber, and L. Bucsis, Makromol. Chem., 136, 303 (1970).

10. H. Schott and G. Greber, Makromol. Chem., 136, 307 (1970).

11. T. Ueda, K. Nakatani, K. Konto, K. Takemoto, and M. Imoto, Makromol. Chem., 134, 305 (1970).

12. J. Pitha and P. M. Pitha, Science, 172, 1146 (1971).

13. R. C. Laible, Chem. Rev., 58, 807 (1958).

14. D. H. Solomon, J. Polym. Sci. Symp, 49, 175 (1975).

15. A. Matsumoto, K. Iwanami, and M. Oiwa, J. Polym. Sci., Polym. Lett., 19, 497 (1981).

16. A. Matsumoto, K. Iwanami, and M. Oiwa, J. Polym. Sci., Polym. Lett., 18, 211 (1980).

17. A. Matsumoto, K. Iwanami, and M. Oiwa, J. Polym. Sci., Polym. Chem., 19, 213 (1981).

18. D. Babilis, L. H. Margaritis and C. M. Paleos, J. Polym. Sci., Polym. Chem., 19, 213 (1981).
19. C. M. Paleos, Ph. Dais, and A. Malliaris, J. Polym. Sci., Polym. Chem., 22, 3383 (1984).

20. B. H. Rizkalla and A. D. Broom, J. Org. Chem., 37, 3980 (1972).

21. J. I. Matsumoto, H. Sogo, and S. Minami, Chem. Pharm. Bull., 28, 2148 (1980).

22. D. J. Brown, The Pyrimidines, Supplement I, Wiley-Interscience, New York, 1970, p. 244.

23. K. Miura, M. Ikada, T. Oohashi, Y. Igarashi, and I. Okada, Ueda, Chem. Pharm. Bull, 13, 529 (1965).

24. C. G. Beddows, V. Bilgin, M. H. Gill, J. Green, J. T. Guthrie, S. Kotov, R. Morris, and D. Resendez, in Radiation Technology for the Immobilisation of Bioactive materials IAEA-TECDOC, Vienna, 1988, p. 69.

25. S. Venkataraman, T. A. Horbett, and A. S. Hoffman, Am. Chem. Soc. Polym. Prep., 16, 197 (1975).

26. A. S. Hoffman, W. R. Grombotz, S. Venoyama, L. C. Dong, and G. Schmer, Radiat. Phys. Chem., 27, 265 (1986).

27. C. G. Beddows, M. H. Gill and J. T. Guthrie, Polym. Photochem., 1, 83 (1986).

28. C. G. Beddows, M. H. Gill, and J. T. Guthrie, Polym. Photochem., 1, 213 (1986).

29. J. Rosiak, K. Burczak, T. Czolczynska, and W. Pekala, Radiat. Phys. Chem., 22, 917 (1983).

30. A. Rucinska-Rybus, J. Rosiak, and W. Pekala, $R a-$ diat. Phys. Chem., 24, 495 (1985).

31. M. Kumakura, I. Kaetsu, and K. Nishikawa, Biotechnol. Bioeng., 26, 17 (1984).

32. M. Kumakura, I. Kaetsu, S. Adachi, and M. Suzuki, Appl. Biochem. Biotechnol., 8, 87 (1983).

33. J. Woodward, Immobilised Cello and EnzymesA Practical Approach, IRL Press, Oxford, 1985.

34. M. H. Gill, Ph.D. thesis, University of Leeds, 1982.

35. C. G. Beddows, J. T. Guthrie, and R. A. Morris, Biotechnol. Appl. Biochem., 16, 181 (1986).

36. C. G. Beddows, M. H. Gill and J. T. Guthrie, Biotechnol. Bioeng., 28, 52 (1986).

37. F. I. Abdel-Hay, J. T. Guthrie, and C. G. Beddows, Biotech. Bioeng., 23, 2885 (1981).

38. C. G. Beddows, M. H. Gill and J. T. Guthrie, Polym. Bull., 3, 645 (1980).

39. I. Kaetsu, in Radiation Technology for the Immobilisation of Bioactive Materials, IAEA-TECDOC, Vienna, 1988, p. 113.

40. M. Yoshida, M. Kumakura, and I. Kaetsu, J. Macromol. Sci., Chem., A14, 541 (1980).

41. J. Green, Ph.D. thesis, University of Leeds, 1989.

42. G. Tsatsaronis and F. Effenberger, Chem. Ber., 94, 2876 (1961)

43. T. Koyama, T. Hirota, M. Ikeda, T. Setoh, A. Iwadoh, and S. Ohuiori, Chem. Pharm. Bull., 23, 917 (1975).

44. S. Pegiadou-Koemtjopoulou, J. Heterocycl. Chem., 23, 1063 (1986).

45. K. Miura, M. Ikeda, T. Oohashi, Y. Igarashi, and I. Okada, Chem. Pharm. Bull., 13, 529 (1965). 